Purdue University

Purdue e-Pubs

CTRC Research Publications

Cooling Technologies Research Center

2012

\title{
Thermomechanical Simulation of the Solar One Thermocline Storage Tank
}

\author{
S. Flueckiger \\ Purdue University \\ Z. Yang \\ Purdue University \\ S V. Garimella \\ Purdue University, sureshg@purdue.edu
}

Follow this and additional works at: http://docs.lib.purdue.edu/coolingpubs

Flueckiger, S.; Yang, Z.; and Garimella, S V., "Thermomechanical Simulation of the Solar One Thermocline Storage Tank" (2012). CTRC Research Publications. Paper 232.

http://dx.doi.org/DOI: 10.1115/1.4007665

This document has been made available through Purdue e-Pubs, a service of the Purdue University Libraries. Please contact epubs@purdue.edu for additional information. 


\section{Scott M. Flueckiger \\ School of Mechanical Engineering, Purdue University, \\ 585 Purdue Mall, \\ West Lafayette, IN 47907-2088}

Zhen Yang
Key Laboratory for Thermal Science and Power
Engineering of Ministry of Education,
Department of Thermal Engineering,
Tsinghua University,
Beijing 100084, China
Suresh V. Garimella $\mathbf{1}$
School of Mechanical Engineering,
Purdue University,
585 Purdue Mall,
West Lafayette, IN 47907-2088
e-mail: sureshg@purdue.edu

\section{Thermomechanical Simulation of the Solar One Thermocline Storage Tank}

\begin{abstract}
The growing interest in large-scale solar power production has led to a renewed exploration of thermal storage technologies. In a thermocline storage system, heat transfer fluid (HTF) from the collection field is simultaneously stored at both excited and dead thermal states inside a single tank by exploiting buoyancy forces. A granulated porous medium included in the tank provides additional thermal mass for storage and reduces the volume of HTF required. While the thermocline tank offers a low-cost storage option, thermal ratcheting of the tank wall (generated by reorientation of the granular material from continuous thermal cycling) poses a significant design concern. A comprehensive simulation of the $170 \mathrm{MWh}$ thermocline tank used in conjunction with the Solar One pilot plant is performed with a multidimensional two-temperature computational fluid dynamics model to investigate ratcheting potential. In operation from 1982 to 1986, this tank was subject to extensive instrumentation, including multiple strain gages along the tank wall to monitor hoop stress. Temperature profiles along the wall material are extracted from the simulation results to compute hoop stress via finite element models and compared with the original gage data. While the strain gages experienced large uncertainty, the maximum predicted hoop stress agrees to within $6.8 \%$ of the maximum stress recorded by the most reliable strain gages. [DOI: 10.1115/1.4007665]
\end{abstract}

Keywords: thermocline, thermal ratcheting, Solar One, concentrating solar thermal power

\section{Introduction}

Concentrated solar power (CSP) refers to the conversion of focused sunlight into heat for steam generation in a power cycle. The intermediate step involving the conversion of energy into heat provides an inherent potential for the inclusion of thermal energy storage in CSP plants. Without storage, CSP plant performance is subject to random cloud transients, planetary rotation, and seasonal effects which limit solar collection and subsequent steam generation at multiple time scales. This leads to an undesirable variable output and requires an auxiliary backup source that is typically fossil-fuel-based. Thermal storage can mitigate the variability and intermittency of solar electricity generation by providing a buffer between the collection of sunlight and the generation of steam. A variety of storage technologies have been investigated in the literature with a preponderance of sensible heat storage due to its low cost and design simplicity relative to other thermal storage mechanisms. With sensible heat storage, an excess volume of HTF is heated from the solar collector field and stored in an auxiliary reservoir. During periods of low insolation, this heated fluid volume is dispatched to generate steam in the Rankine cycle as needed. A molten-salt thermocline tank offers the lowest potential cost relative to other sensible heat storage implementations [1].

In a thermocline storage tank, hot and cold HTFs are stored inside a single tank, separated via buoyancy forces. A large temperature gradient develops at the interface of the two isothermal regions, known as the heat-exchange or thermocline region. This region is not fixed in time, but instead travels along the tank axis as heated HTF is either added or removed from the tank volume. Addition of hot fluid from the collection field is designated as a

\footnotetext{
${ }^{1}$ Corresponding author.

Contributed by the Solar Energy Division of ASME for publication in the Journal of Solar EnERgy EngineERING. Manuscript received October 24, 2011; final manuscript received September 6, 2012; published online October 17, 2012. Assoc. Editor: Rainer Tamme.
}

charge process, while removal of the hot fluid for steam generation is designated as a discharge process. The use of molten salt as the HTF enables higher operating temperatures and lower material costs relative to the more prevalent synthetic oils [2]. Further cost savings are achieved by introducing low-cost filler material into the tank to reduce the volume of fluid required. The filler material is granulated to inhibit thermal conduction in the axial direction, which would be detrimental to the desired stratification. Quartzite rock and silica sand are the most suitable filler materials due to their low cost, chemical inertness, and physical stability under repeated thermal cycling [3].

Despite these economic and performance advantages, a critical design consideration associated with a thermocline tank is the potential for failure via thermal ratcheting. In response to the cyclic operation of hot and cold HTFs, large temperature fluctuations develop along the height of the thermocline tank. The resultant physical interaction between the tank wall and the internal filler is a function of the material coefficients of thermal expansion. If the thermal expansion of the tank wall exceeds that of the filler, an annular gap develops between the materials when the tank is heated (i.e., the charge process). The granulated filler reorients (slumps) to fill this gap. After this reorientation, the tank wall has "ratcheted" to a new diameter and can no longer contract to its original shape during the subsequent discharge process due to the resistance posed by the rearranged filler. A portion of the thermal strain generated from the charge process converts to mechanical strain and carries a finite amount of stress. If this stress exceeds the yield strength of the wall material, the wall plastically deforms and prevents full recovery of the thermal strain in subsequent tank cycles. Additional strain is then generated during the ratcheting in each successive operation cycle, leading to the accumulation of ratchets and the possibility of catastrophic tank failure.

Thermal ratcheting is a complex interaction of thermal transport and solid mechanics, which has not been widely studied for thermocline storage tanks. Flueckiger et al. recently investigated thermal ratcheting via a computational fluid dynamics (CFD) 
simulation of a thermocline storage volume enclosed with a composite wall [4]. Heat exchange in the dual-media fillerbed was resolved with a two-temperature approach in which the thermal transport in the porous bed and the molten salt is treated separately (and not as a homogeneous mixture), similar to previous investigations [5-7]. The composite wall design considered in Ref. [8] was based on a multilayer concept proposed in Ref. [4], with the wall being composed of a steel shell encased on both sides by separate layers of insulation material (internal and external). A parametric analysis of the individual layer thickness and external heat losses was performed to assess optimal designs that could inhibit ratcheting behavior. The stress induced in the steel shell was deduced from the shell temperature oscillations that were generated by the cyclic charge and discharge processes. Due to the magnitude of hoop stress relative to the other principal stresses, a one-dimensional analytical approach was sufficient to relate temperature, strain, and stress.

From the parametric study, increased thickness of internal insulation greatly reduced stress levels by buffering the influence of the cyclic molten-salt temperatures. Conversely, hoop stress also decreased upon a reduction of the external insulation due to greater influence of the surroundings on the steel shell temperature. However, it should be noted that both insulation layers also serve to inhibit energy losses from the fillerbed to the surroundings, and the tank design carries a trade-off between these two consequences of the insulation. Results from this composite wall analysis by Flueckiger and Zamparelli could not be validated against real data as the multilayer concept proposed in Ref. [8] was not experimentally verified. In order to validate the theoretical modeling approach developed here for thermal ratcheting, measured temperature fields and wall stresses from historic thermocline tanks are necessary. Such information is available in the published literature for the thermocline tank operated as part of the Solar One facility [9-12].

Solar One was a central-receiver CSP pilot plant installed outside Barstow, California in operation from 1982 to 1987 [9]. Using direct steam generation (DSG), hundreds of heliostats focused incident sunlight onto a single receiver tower housing a boiler. This boiler was integrated into a Rankine cycle, which powered a generator capable of $10 \mathrm{MW}_{\mathrm{e}}$ output. Despite the advantages of using molten salts in CSP plants, oils were the state-of-the-art HTFs at the time of Solar One. As such, the thermocline tank contained Caloria HT-43 mineral oil in combination with granite rock as the solid filler [10]. Due to the fluid mismatch of the oil and steam, energy transport between the DSG collection loop and the thermal storage system was implemented with heat exchangers.

While the design point of the Solar One boiler was $516^{\circ} \mathrm{C}$, the Caloria oil was constrained to temperatures below $316^{\circ} \mathrm{C}$ to avoid vaporization. This large drop in thermal quality inhibited operation of the storage system for power generation. In practice, the tank operated from $204{ }^{\circ} \mathrm{C}$ to $304{ }^{\circ} \mathrm{C}$, primarily for auxiliary steam generation. As the first large-scale CSP plant to have been in operation, the entire Solar One facility was subject to extensive instrumentation and data collection. For the thermal storage system, temperatures during operation cycles as well as stresses monitored along the tank wall are available. The CFD simulation undertaken in the present work simulates the conditions experienced by the Solar One thermocline tank in an effort to validate the structural modeling approach and to predict whether the conditions of operation would lead to thermal ratcheting in the tank wall.

\section{Numerical Modeling}

2.1 Problem Description. The numerical simulation considers a model of the original Solar One thermocline as described in published schematic diagrams [11,12], and illustrated in Fig. 1. The tank is composed of a carbon steel wall (ASTM 537 class 2) of $9.1 \mathrm{~m}$ inner radius, constructed above a $0.6 \mathrm{~m}$ base layer of concrete. In the original tank, this steel wall included discrete sections of different thicknesses, varying from $2.89 \mathrm{~cm}$ at the bottom to

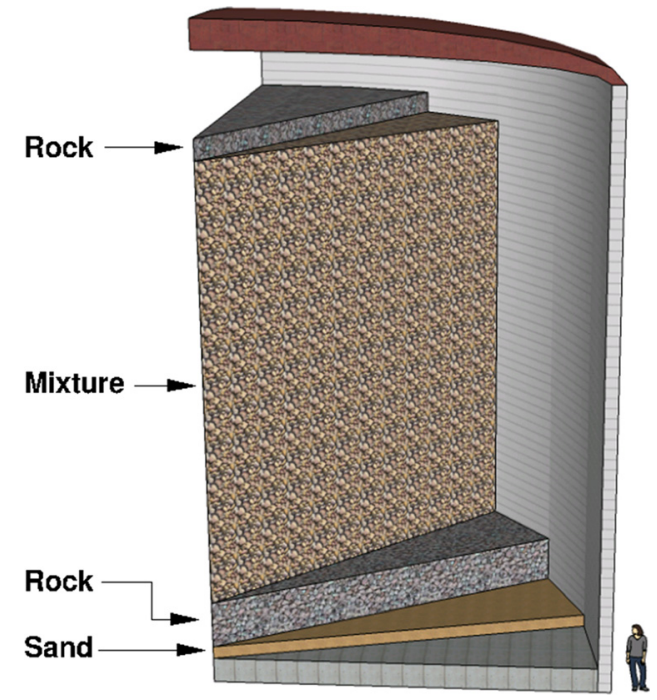

Fig. 1 Cutaway representation of Solar One thermocline tank

$0.79 \mathrm{~cm}$ near the top. For simplicity, the model wall geometry is fixed to an intermediate and constant thickness of $2 \mathrm{~cm}$. The steel shell is surrounded with a $0.3 \mathrm{~m}$ layer of fiberglass insulation while the top of the tank is enclosed with a $0.6 \mathrm{~m}$ layer of calcium silicate to inhibit external heat losses.

Inside the thermocline tank, the granite filler is composed of two distinct sizes, sand and rock, which are stratified along the tank axis. From the tank floor, these stratified regions include a $0.3 \mathrm{~m}$ thick layer of sand, a $1.1 \mathrm{~m}$ layer of rock, a $10.5 \mathrm{~m}$ layer of rock and sand mixture, and a final $0.5 \mathrm{~m}$ layer of rock. For simulation, the size of the granite sand and rock is fixed to effective diameters of $0.2 \mathrm{~cm}$ and $5 \mathrm{~cm}$, respectively. In the mixture layer, a weighted average diameter of $0.46 \mathrm{~cm}$ is assumed. In the monodisperse layers, a bed porosity of 0.4 is employed while the porosity of the mixture layer is reduced to 0.22 . Above the filler, nitrogen gas fills the remaining tank volume and is treated as a quiescent fluid. The thermal properties of the solid materials and nitrogen gas are listed in Table 1.

During a charge process, Caloria oil heated from the collection loop is pumped into the top of the filler region at a temperature of $304^{\circ} \mathrm{C}$ while colder fluid exits at the bottom. For a discharge, the fluid flow is reversed such that unheated Caloria enters the bottom of the filler region at $204{ }^{\circ} \mathrm{C}$ to deliver heated oil from the top. The density, kinematic viscosity, and thermal conductivity of the Caloria are defined as functions of temperature derived from experimental data [10]

$$
\begin{gathered}
\rho_{1}\left(T_{1}\right)=-0.713 T_{1}+871.1 \\
\nu\left(T_{1}\right)=0.0452\left(T_{1}^{-1.943}\right) \\
k_{1}\left(T_{1}\right)=-0.00014 T_{1}+0.125
\end{gathered}
$$

Upper and lower distributor manifolds were installed in the monodisperse rock layers to transport oil to and from the

Table 1 Thermal transport properties of Solar One thermocline tank materials

\begin{tabular}{lcccc}
\hline \hline Material & $k(\mathrm{~W} / \mathrm{m} \mathrm{K})$ & $\rho\left(\mathrm{kg} / \mathrm{m}^{3}\right)$ & $C_{\mathrm{P}}(\mathrm{J} / \mathrm{kg} \mathrm{K})$ & Reference \\
\hline Carbon steel & 47.0 & 7850 & 475 & {$[13]$} \\
Calcium silicate & 0.080 & 250 & 840 & {$[13]$} \\
Fiberglass & 0.038 & 32 & 835 & {$[14]$} \\
Cement & 0.720 & 1860 & 780 & {$[14]$} \\
$\mathrm{N}_{2}$ ullage & 0.043 & 0.585 & 1070 & {$[14]$} \\
\hline \hline
\end{tabular}

Note: Reference cited in the table is [14]. 
thermocline tank as needed. For simulation, these distributors are represented with two thin regions of mass and energy generation within the rock layers. When the tank undergoes a simulated charge, mass and energy are generated inside the upper rock layer while mass and energy are simultaneously destroyed in the lower rock layer resulting in a net fluid flow. For the discharge phase, the signs of mass and energy generation are switched to produce the reverse flow condition. The governing equations (discussed in Sec. 2.2) within the designated transport regions are modified in the commercial solver FLUENT with user-defined source and sink terms to enforce this artificial generation and destruction.

Mass transport of oil to the thermocline tank was determined from documented charge and discharge operations to approximate the original tank performance. Available data include a Mode 5 charge performed on May 19, 1983 [11]. In Mode 5 operation, all steam generated from the collection processes is diverted to the thermal storage system to charge the tank. (In other charging modes, only a portion of steam is sent to the storage system while the remaining steam stays within the Rankine cycle flow loop to generate electrical power.) The mass flow of the heated Caloria into the tank lasted approximately $9 \mathrm{~h}$ and is plotted in Fig. 2.

It was noted in Ref. [12] that given the large physical scale of the Solar One facility, flow rate measurements were affected by leaks and subject to inaccuracies; an estimated 15-20\% positive bias was reported in the oil flow measurements. A corrected flow rate with a $20 \%$ reduction from the original data is included in Fig. 2. An average volumetric flow rate is then determined as an input to the 9-h charge simulation. For the artificial distributor volume used, this flow rate implies a required mass generation rate of $1.804 \mathrm{~kg} / \mathrm{m}^{3} \mathrm{~s}$. An equivalent mass generation rate and duration are applied for the subsequent discharge process. Along with mass generation, the simulated distributor regions generate energy based on the fluid enthalpy

$$
P^{\prime \prime \prime}=\dot{m}^{\prime \prime \prime} C_{\mathrm{P}, 1}\left(T_{1}-T_{0}\right)
$$

As in the real tank, the charge and discharge are separated by periods of standby where Caloria is not actively transported through the thermocline tank. These standby periods extend for $15 \mathrm{~h}$ to complete simulation of the 24-h day.

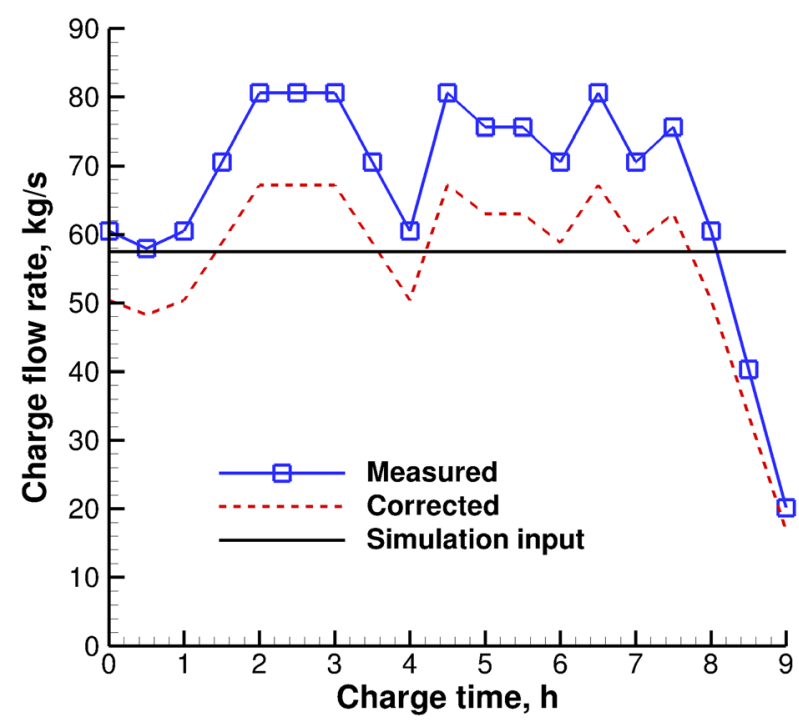

Fig. 2 Solar One thermocline tank charge profile. Measured values were known to exhibit up to $20 \%$ bias. A subsequent corrected and time-averaged value is enforced for input to the simulation.

\subsection{Governing Equations}

2.2.1 Caloria Fluid Flow and Heat Transfer Inside the Thermocline Tank. Inside the fillerbed, fluid flow of the Caloria oil is governed by the following mass and momentum transport equations [5]:

$$
\begin{gathered}
\frac{\partial\left(\phi \rho_{1}\right)}{\partial t}+\nabla \cdot\left(\rho_{1} \mathbf{u}\right)=0 \\
\frac{\partial\left(\rho_{1} \mathbf{u}\right)}{\partial t}+\nabla \cdot\left(\rho_{1} \frac{\mathbf{u u}}{\phi}\right)= \\
-\phi \nabla p+\nabla \cdot \tilde{\tau}+\phi \rho_{1} \mathbf{g} \\
-\phi\left(\frac{\mu}{K} \mathbf{u}+\frac{F}{\sqrt{K}} \rho_{1}|\mathbf{u}| \mathbf{u}\right)
\end{gathered}
$$

The stress deviator tensor is defined as $\tilde{\tau}=2 \mu \tilde{\mathbf{S}}-(2 / 3) \mu S_{k k} \tilde{\mathbf{I}}$, where $\tilde{\mathbf{S}}=(1 / 2)\left(\nabla \mathbf{u}+(\nabla \mathbf{u})^{T}\right)$ is the rate of strain tensor. For polar coordinates, the spatial gradient is $\nabla=\mathbf{e}_{r}(\partial / \partial r)+\mathbf{e}_{\theta}(1 / r)$ $(\partial / \partial \theta)+\mathbf{e}_{x}(\partial / \partial x)$. The thermocline geometry is assumed to be axisymmetric, thus eliminating any velocity or functional dependencies in the circumferential direction.

Energy transport in the fillerbed is governed by a twotemperature model with distinct equations for the fluid (subscripted 1) and solid filler (subscripted s) [5]

$$
\begin{gathered}
\frac{\partial\left(\phi \rho_{\mathrm{l}} C_{\mathrm{P}, 1} T_{1}\right)}{\partial t}+\nabla \cdot\left(\rho_{\mathrm{l}} \mathbf{u} C_{\mathrm{P}, 1} T_{\mathrm{l}}\right)=\nabla \cdot\left(k_{\mathrm{eff}} \nabla T_{1}\right)+h_{\mathrm{v}}\left(T_{\mathrm{s}}-T_{1}\right) \\
\frac{\partial}{\partial t}\left[(1-\phi) \rho_{\mathrm{s}} C_{\mathrm{P}, \mathrm{s}} T_{\mathrm{s}}\right]=-h_{\mathrm{v}}\left(T_{\mathrm{s}}-T_{1}\right)
\end{gathered}
$$

The two equations are coupled by porous media forced convection. The volumetric heat transfer coefficient $h_{\mathrm{v}}$ is derived from the Wakao and Kaguei correlation for forced convection inside a packed bed [15]. In the remaining solid materials and quiescent ullage space, thermal transport is solved with the axisymmetric heat diffusion equation.

2.2.2 Boundary Conditions. Due to the elevated temperatures of the Caloria, a portion of the stored heat is lost from the tank to the surroundings. Accounting for convection and conduction, this heat loss is governed by

$$
\left.k_{2} \frac{\partial T}{\partial r}\right|_{\mathrm{w}}=-h_{\mathrm{w}}\left(T_{\mathrm{w}}-T_{\infty}\right)-\varepsilon_{\mathrm{w}} \sigma_{\mathrm{r}}\left(T_{\mathrm{w}}^{4}-T_{\infty}^{4}\right)
$$

The convection coefficient $h_{\mathrm{w}}$ at the tank surface (sidewall and top) and ambient temperature are estimated to be $2.2 \mathrm{~W} / \mathrm{m}^{2} \mathrm{~K}$ and 294 K, respectively; informed by weather reports for May 1983 in Barstow, California [16]. The surface emissivity is fixed to 0.9 as a conservative estimate. The floor of the cement base is assumed to be adiabatic.

2.2.3 Mechanical Stress. To model the wall stress associated with thermal cycling of the thermocline tank, the internal filler is assumed to be cohesionless (no resistance to slumping) and infinitely rigid (immune to mechanical deformation). The result is a conservative approximation of the true bed behavior in which stress is proportional to the magnitude of temperature fluctuations inside the steel wall, as discussed below.

From the solved temperature fields, the associated radial deformation of the steel wall is a function of the thermal strain

$$
\varepsilon_{\mathrm{T}}(x, r)=\alpha_{\mathrm{L}}\left[T_{1}(x, r)-T_{\text {ref }}\right]
$$

When the steel is heated to a maximum temperature during tank operation, the associated thermal strain also reaches a maximum value. Due to the thermal stratification inside the tank, this maximum and the time of its occurrence vary along the axial tank 
height. Since the internal filler does not prevent outward expansion of the tank wall, the mechanical strain at this time is zero. Strain interaction with the fiberglass insulation layer is neglected as the fiberglass does not provide structural support to the thermocline assembly. As the granite filler is assumed to exhibit infinite rigidity, the wall cannot contract and the maximum amount of strain remains constant in the circumferential direction. When the steel attempts to contract from subsequent cooling, a portion of this thermal strain converts to mechanical strain. At the coldest time during the cycle, the thermal strain is at a minimum and the mechanical strain is at a maximum. The stress distribution resulting from this mechanical strain is governed by Hooke's Law

$$
\varepsilon_{\mathrm{M}}(x, r)=\frac{1}{E}\left[\sigma_{11}-\nu_{\mathrm{P}}\left(\sigma_{22}+\sigma_{33}\right)\right]
$$

While the weight of the fillerbed and oil exert some pressure on the tank wall, the resultant stress is negligible relative to the stress associated with the permanently expanded tank radius. Thus, the functional dependence of mechanical strain in Eq. (11) may be simplified to a single principal stress, i.e., the hoop stress. If this hoop stress exceeds the yield strength of the steel, the resultant plastic deformation prevents full recovery of the original thermal strain. The total strain value increases with future cycles, enabling the hoop stress to further increase until an eventual tank rupture. Thus, the maximum stress at a given location along the tank wall (governed by the maximum temperature difference) should not exceed the material yield strength $\sigma_{\mathrm{y}}$ to ensure prevention of thermal ratcheting

$$
\sigma_{\max }(x, r)=\alpha_{\mathrm{L}} E\left[T_{1, \max }(x, r)-T_{1, \min }(x, r)\right]<\sigma_{\mathrm{y}}
$$

For mechanical analysis of the carbon steel wall, the coefficient of thermal expansion and modulus of elasticity are fixed to $13 \mu \mathrm{m} / \mathrm{m} \mathrm{K}$ and $140 \mathrm{GPa}$, respectively [13]. The yield strength for the applied wall thickness is $414 \mathrm{MPa}$ [17].

2.3 Solution Algorithm. Governing equations for the thermal analysis are solved with the commercial CFD software, FLUENT 12.1.14 [18]. The internal volume and wall domains are discretized into a structural nonuniform grid of 117,355 cells for finite-volume computation. Spatial discretization of the convective fluxes is performed with a second-order upwind scheme. Transient discretization is performed with a first-order implicit formulation. Prior to simulation, the entire thermocline tank domain is initialized to the cold Caloria oil limit of $204{ }^{\circ} \mathrm{C}$. Due to external losses from the tank to the surroundings, this initial condition is not realized during operation and implies some discrepancy between experiment and simulation. Multiple operation cycles must therefore be simulated in sequence to eliminate this discrepancy in the temperature fields, indicated when periodicity develops throughout the domain. For the Solar One thermocline tank model, a periodic response required seven full cycles of simulated operation.

After periodicity is achieved, the vertical temperature distribution of the steel shell is extracted from the solved temperature field at multiple times throughout the full operation cycle. The maximum and minimum steel temperatures at each discretized cell along the tank wall are then extracted from these instantaneous profiles. These limiting values are combined to generate two separate profiles representative of the maximum and minimum temperatures experienced at each discrete location during one full operation cycle. The maximum temperature profile represents the final shape and relative position of the tank wall as a result of thermal expansion. With the solid filler assumed to be a rigid body when under radial compression, the minimum temperature profile determines the maximum amount of hoop stress that develops due to the inability of the wall to contract around the reoriented filler. In addition, the interface between the steel shell and the cement base is assumed to be fixed. To employ this constraint, an axisymmetric model of the steel shell is constructed in the commercial finite element analysis (FEA) software, ANSys 12.1 [19]. The maximum temperature profile is applied along the wall height to determine the maximum radial wall deformation. This deformation is then fixed while the minimum temperature profile is applied to solve for hoop stress.

\section{Results and Discussion}

A plot of the entire temperature field at hour 30 of the 2-day cycle is plotted in Fig. 3. As seen, the hot and cold Caloria fluid volumes successfully stratify inside the filler region. Instantaneous temperature profiles along the steel shell during the 2-day operation cycle are provided in Fig. 4. The temperature profiles are plotted at 3-h intervals for the charge (hours 3, 6,9) and discharge (hours 27, 30,33) processes. Also plotted are the final temperature profiles for both standby periods (hours 24 and 48). Upon inspection, the largest temperature fluctuations occur between 1 and $9 \mathrm{~m}$ along the tank height, indicating the travel path of the heatexchange region separating the hot and cold Caloria reservoirs. During the charging process, the heat-exchange region moves downward as additional hot Caloria is added at the top of the filler region. At the end of the charge, this region remains relatively stationary throughout the subsequent standby period as expected. During discharge, the heat-exchange region reverses direction and travels upward due to the addition of cold Caloria at the bottom of the filler region. After completion of the second standby period, the region has returned to its initial location to begin the cycle anew. The time-independent maximum and minimum temperature profiles explained in Sec. 2.3 are then extracted for the FEA deformation study.

The results of the FEA simulation are plotted in Fig. 5. An increased plateau of hoop stress exists from a height of 2 to $8 \mathrm{~m}$ along the steel shell, with a maximum value of $177 \mathrm{MPa}$. As the stress profile is time-independent, the span of maximum hoop stress is explained by the vertical motion of the heat-exchange region in the tank. Outside the travel path of the heat-exchange region, the steel shell is exposed to relatively isothermal Caloria oil and experiences greater thermal stability. This stability in turn allows for reduced stress levels, indicated by the drop in hoop stress along the steel shell above $8 \mathrm{~m}$. Small increases in stress located at the top of the tank wall are attributed to edge effects.

In the original tank, individual strain gages were installed at various heights and azimuth angles along the steel shell. Horizontal stress data from these gages recorded in June 1984 are included

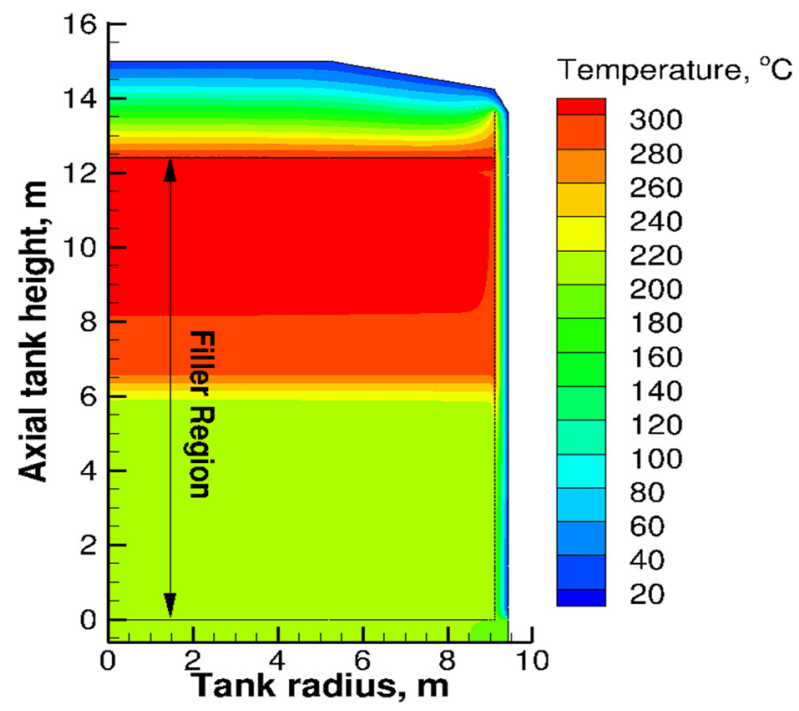

Fig. 3 Temperature field in the thermocline tank (hour 30) 


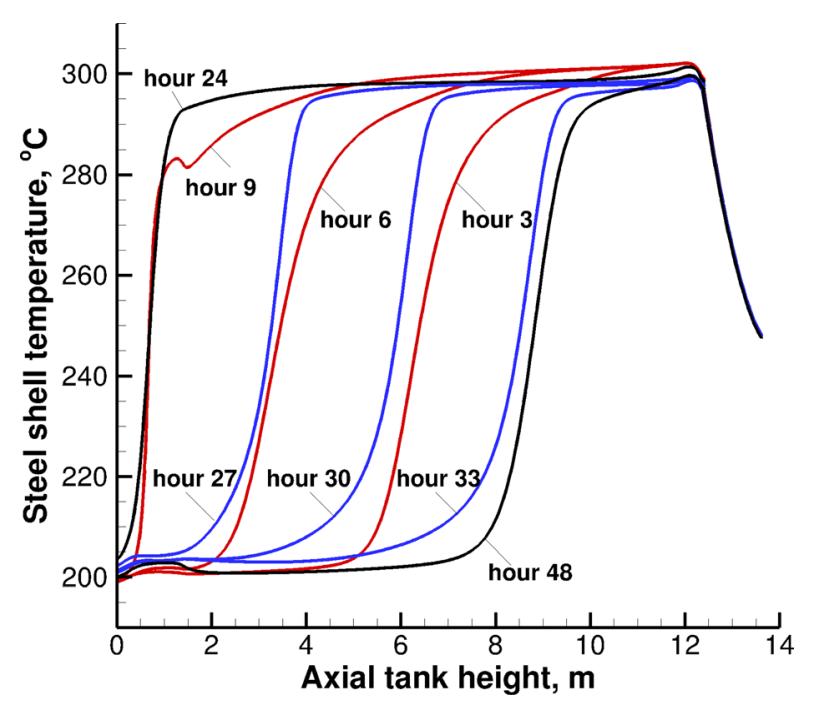

Fig. 4 Steel shell temperature profiles throughout simulated thermocline tank operation

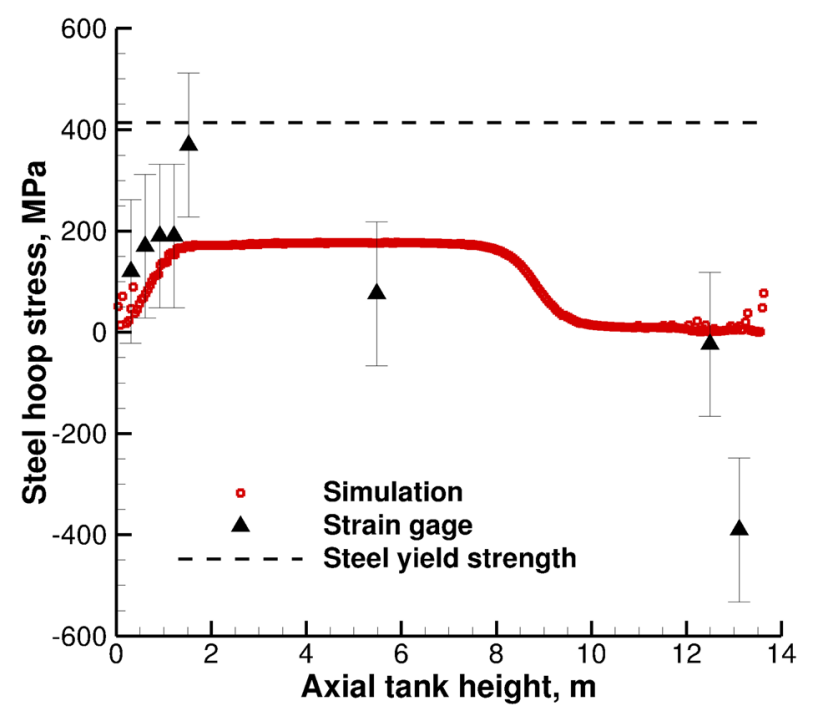

Fig. 5 Solar One thermocline tank hoop stress (simulation and measured [12])

in Fig. 5 [12]. While the general trend of the simulated values agrees with the measurements, discrepancies in the comparison may be attributed to the somewhat idealized nature of the CFD model (the original thermocline tank was never operated in such a consistent, periodic manner), and to the large uncertainties of up to $142 \mathrm{MPa}$ in the physical gage readings. This documented gage uncertainty is included in Fig. 5 as error bars. The original report for the thermocline tank [12] attributes these uncertainties to the scale, complexity, and novelty of the Solar One facility. Data obtained between $0.6096 \mathrm{~m}$ and $1.219 \mathrm{~m}$ exhibited the most consistent and valid readings. Within this region, the measured horizontal stress achieves a maximum value of $190 \mathrm{MPa}$, a $6.8 \%$ deviation from the maximum stress of $177 \mathrm{MPa}$ determined from the numerical investigation. Data along the wall at 0.3408, 5.486, and 12.5 are also within the range of uncertainty for the gage measurements at these positions. Given this reasonable similarity in datasets, it may be inferred that the modeling approach successfully predicts hoop stress along the tank wall.

The stress results are also compared with the yield strength of the steel, included in Fig. 5, to assess the potential for thermal ratcheting. At $414 \mathrm{MPa}$, the yield strength exceeds the recorded hoop stresses (numerical and strain gage), signifying a successful prevention of the plastic deformation necessary for ratchet accumulation. While the uncertainty in gage data reported at $1.524 \mathrm{~m}$ exceeds the yield strength, the actual value may have been lower as the tank did not fail from thermal ratcheting during its operational lifetime.

It should be noted that the present analysis is limited to cyclic charge and discharge of the Solar One thermocline tank. If the tank undergoes a complete shutdown or startup with respect to the ambient, the magnitude of temperature variation in the tank wall increases by nearly a factor of 3 . In this scenario, the infinite rigidity approximation of the granulated filler becomes overly conservative and yields excessive values of hoop stress. In reality, the solid filler undergoes some finite amount of volume change due to thermal expansion and mechanical interactions with its surroundings. As the magnitude of temperature variation along the tank wall increases, the change in granulated filler volume increases and the filler behavior further deviates from the infinite rigidity model applied in the present investigation. A detailed model of the granular physics inside the tank must be implemented to model such a startup or shutdown process.

\section{Conclusions}

A detailed CFD simulation of the original Solar One thermocline tank is performed to validate a model for hoop stress determination and thermal ratcheting potential. Assuming negligible deformation of the filler granules (infinite rigidity), hoop stress in the steel shell of the tank model is readily determined from periodic temperature profiles, which dictate the maximum permanent deformation of the steel. The results of the Solar One simulation predict a wide band of maximum hoop stress across the lower half of the thermocline tank, attributed to the moving heat-exchange region inside the tank during operation.

Data taken from the most reliable gages agreed with the stress maximum predicted from the numerical investigation to within $13 \mathrm{MPa}$ or $6.8 \%$. Both results were less than the yield strength of the applied steel, thus avoiding catastrophic thermal ratcheting. From this localized agreement with measured results from the Solar One project [12], the applied modeling approach is considered suitable for thermal ratcheting analysis of cyclic dual-media thermocline tanks. However, model accuracy and versatility can be further improved by including additional submodels related to the internal granular physics so that the infinite rigidity approximation may be relaxed.

\section{Nomenclature}

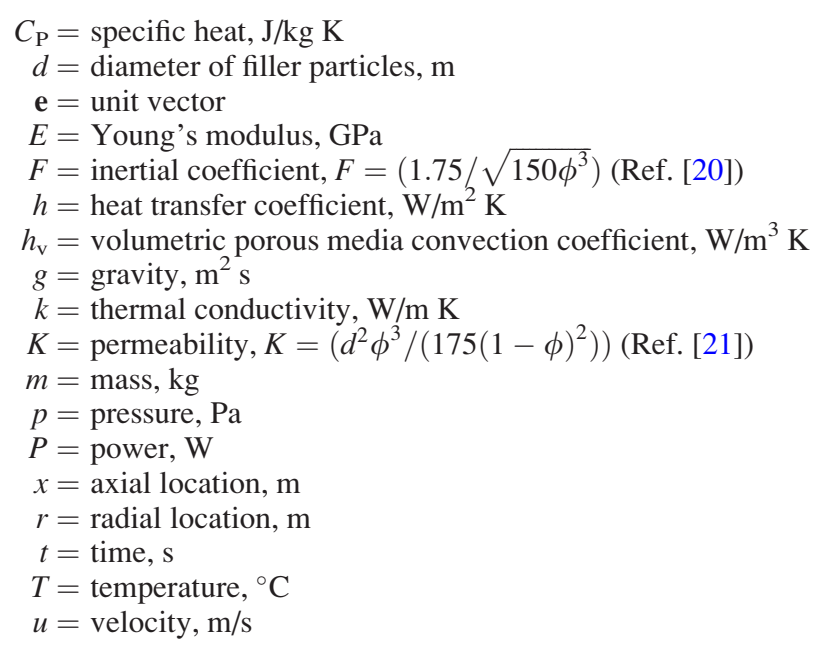

\section{Greek Symbols}

$$
\begin{aligned}
\alpha_{\mathrm{L}} & =\text { coefficient of linear thermal expansion, } \mu \mathrm{m} / \mathrm{m} \mathrm{K} \\
\varepsilon & =\text { strain }
\end{aligned}
$$




$$
\begin{aligned}
\varepsilon_{\mathrm{r}} & =\text { emissivity } \\
\rho & =\text { density, } \mathrm{kg} / \mathrm{m}^{3} \\
\sigma & =\text { stress, } \mathrm{Pa} \\
\sigma_{\mathrm{r}} & =\text { Stefan-Boltzmann constant, } 5.67 \times 10^{-8} \mathrm{~W} / \mathrm{m}^{2} \mathrm{~K}^{4} \\
\mu & =\text { viscosity } \\
\nu & =\text { kinematic viscosity, } \mathrm{m}^{2} / \mathrm{s} \\
\nu_{\mathrm{p}} & =\text { Poisson's ratio } \\
\phi & =\text { porosity }
\end{aligned}
$$

\section{Subscripts}

$$
\begin{aligned}
0 & =\text { dead state } \\
1 & =\text { steel tank layer } \\
2 & =\text { fiberglass insulation layer } \\
\text { eff } & =\text { effective thermal conductivity } \\
1 & =\text { liquid HTF region } \\
\mathrm{M} & =\text { mechanical strain } \\
\max & =\text { maximum } \\
\min & =\text { minimum } \\
\text { ref } & =\text { reference temperature } \\
\mathrm{s} & =\text { solid filler region } \\
\mathrm{T} & =\text { thermal strain } \\
\mathrm{w} & =\text { wall surface } \\
\mathrm{y} & =\text { yield strength } \\
\infty & =\text { ambient temperature }
\end{aligned}
$$

\section{References}

[1] Libby, C., 2010, Solar Thermocline Storage Systems: Preliminary Design Study, Electric Power Research Institute, Palo Alto, CA, Project 1019581.

[2] Herrmann, U., and Kearney, D. W, 2002, "Survey of Thermal Energy Storage for Parabolic Trough Power Plants,” ASME J. Sol. Energy Eng., 124, pp. 145-152.

[3] Brosseau, D., Kelton, J. W., Ray, D., Edgar, M., Chisman, K., and Emms, B., 2005, "Testing of Thermocline Filler Materials and Molten-Salt Heat Transfer Fluids for Thermal Energy Storage Systems in Parabolic Trough Power Plants," ASME J. Sol. Energy Eng., 207, pp. 109-116.
[4] Flueckiger, S., Yang, Z., and Garimella, S. V., 2011, "An Integrated Thermal and Mechanical Investigation of Molten-Salt Thermocline Energy Storage," Appl. Energy, 88, pp. 2098-2105.

[5] Yang, Z., and Garimella, S. V., 2010, "Thermal Analysis of Solar Thermal Energy Storage in a Molten-Salt Thermocline," Sol. Energy, 84, pp. 974-985.

[6] Yang, Z., and Garimella, S. V., 2010, "Molten-Salt Thermal Energy Storage in Thermocline Under Different Environmental Boundary Conditions," Appl. Energy, 87, pp. 3322-3329.

[7] Yang, Z., and Garimella, S. V., 2012, "Cyclic Operation of Molten-Salt Thermal Energy Storage in Thermoclines for Solar Power Plants," Appl. Energy (in press).

[8] Gabbrielli, R., and Zamparelli, C., 2009, "Optimal Design of a Molten Salt Thermal Storage Tank for Parabolic Trough Solar Power Plants," ASME J. Sol. Energy Eng., 131, p. 041001.

[9] Radosevich, L. G., 1988, "Final Report on the Power Production Phase of the $10 \mathrm{MW}_{\mathrm{e}}$ Solar Thermal Central Receiver Pilot Plant," Sandia National Laboratories, Report No. SAND87-8022.

[10] Honeywell Energy Resources Center, 1977, "Solar Pilot Plant, Phase 1. Preliminary Design Report. Thermal Storage Subsystem," Vol. 5, Contract Report, Report No. SAN1109-87.

[11] McDonnell Douglas Astronautics Company, 1986, "10 MW $\mathrm{MW}_{\mathrm{e}}$ Solar Thermal Central Receiver Pilot Plant Mode 5 (Test 1150) and Mode 6 (Test 1160) Test Report," Contract Report, Report No. SAND86-8175.

[12] Faas, S. E., Thorne, L. R., Fuchs, E. A., and Gilbertsen, N. D., 1986, "10 MW Solar Thermal Central Receiver Pilot Plant: Thermal Storage Subsystem Evaluation-Final Report," Sandia National Laboratories, Report No. SAND86-8212.

[13] Online Materials Information Resource, 2011, http://www.matweb.com

[14] Incropera, F. P., and DeWitt, D. P., 2002, Fundamentals of Heat and Mass Transfer, 5 th ed., John Wiley \& Sons, Hoboken, NJ.

[15] Wakao, N., and Kaguei, S., 1982, Heat and Mass Transfer in Packed Beds, Gordon and Beach, New York.

[16] Weather Underground, 2011, http://www.wunderground.com/history/

[17] ASTM Standard A537, 2008, Standard Specification for Pressure Vessel Plates, Heat-Treated, Carbon-Manganese-Silicon Steel, ASTM International, West Conshohocken, PA.

[18] FlUENT 12.1.4 Documentation, 2011, Fluent Inc., Lebanon, NH

[19] ANSYs 12.1 Documentation, 2011, ANSYS Inc., Lebanon, NH.

[20] Krishnan, S., Murthy, J. Y., and Garimella, S. V., 2004, "A Two-Temperature Model for Analysis of Passive Thermal Control Systems," ASME J. Heat Transfer, 126, pp. 628-637.

[21] Beckermann, C., and Viskanta, R., 1988, "Natural Convection Solid/Liquid Phase Change in Porous Media," Int. J. Heat Mass Transfer, 31, pp. 35-46. 